\title{
A PROTOCOL ON IN VITRO PROPAGATION OF ARBUSCULAR MYCORRHIZAL FUNGI USING ROOT ORGAN CULTURE TECHNIQUE
}

\author{
Hari Prasad Aryal
}

\begin{abstract}
The technique of in vitro propagation of Arbuscular mycorrhizal fungi has been developed over the past few decades and opens up areas of studying plant-fungi interactions. It is a scientific break through, especially for the study of the Arbuscular mycorrhizal fungi, since these obligate symbionts depend on host plant. The objective of this paper is to find out the in vitro culture of Arbuscular Mycorrhizal Fungi using Root Organ Culture technique. Ascertain of root colonization of these fungi could be affected in vitro without undertaking complex and complicated culture conditions. This could form an economically viable technique for root organ culture of Arbuscular mycorrhizal fungi.
\end{abstract}

Key words: In-vitro, arbuscular mycorrhizal fungi, root culture.

\section{INTRODUCTION}

A natural genetic transformation of roots with the soil bacterium and applied to excised roots for the cultivation of Arbuscular Mycorrhizal Fungi (AMF) of this technology is known as the root organ culture technique (ROC), where studying various aspects of the symbiosis. Among the several types of symbiotic associations, the mycorrhizal symbiosis involving plant root and soil fungi is immensely beneficial to plants. Although in AM symbiosis, there is no host specificity, there is host preference and hence mycorrhizal research assumes great significance.

Fungi break down dead organic matter or grow on other organisms to get nutrients for growth. Fungi are major player of Biotechnology. Fungi produce primary and secondary metabolites of industrial importance. Production often occurs after growth has stopped, when nutrients are limited, but excess carbon is available e.g. Penicillin, Cephalosporins, Griseofulvin, Cyclosporin, Ergot alkaloids. They are well developed and understood secretory machinery allowing simple purification of products from culture medium. Fungi are relatively easily grown in mass culture.

Mycorrhizea are mutually beneficial relationship between fungi and plant roots, specifically they are two types. One is ectomycorrhizal fungi, which forms sheaths of hyphae over a root and also grows into the

* Dr. Aryal is Lecturer in Central Department of Botany, Kirtipur, TU. 
extracellular spaces of the root cortex and another is Arbuscular mycorrhizal fungi (AMF), which extends hyphae through the cell walls of root cells and into tubes formed by invagination of the root cell membrane. AMF are symbiotic obligate associations between a group of fungi and the roots of higher plants (Krik, Cannon, Davi \& Stalpers, 2001). AMF colonize approximately 80-90 percentages of terrestrial plants and their beneficial effects on the growth and health of plants have been recognized for some time. However, their obligate biotrophic nature has limited in vitro culture and large-scale production, regarding their potential use as inoculums in agricultural practices (Plenchette, Declerck, Diop \& Strullu, 1996). The principle beneficiary being the host plant due to higher nutrient uptake from the soil and in exchange AMF receive a rhizospheric niche and organic nutrients for its growth and development. This protocol aimed to determine the in vitro propagation of AMF using ROC technique. Therefore, it becomes imperative that the fungi will predominantly flourish only under strict host rhizosphere.

\section{DESCRIPTION}

Fungi not only directly produce substances that humans use as medicine, but they are also versatile tools in the vast field of medical research. Some fungi attack insects and therefore can be used as natural pesticides. Similarly, yeast has been used for thousands of year in the production of alcoholic beverage. The majority of grasses and trees require a mycorrhizeal relationship with fungi to survive.

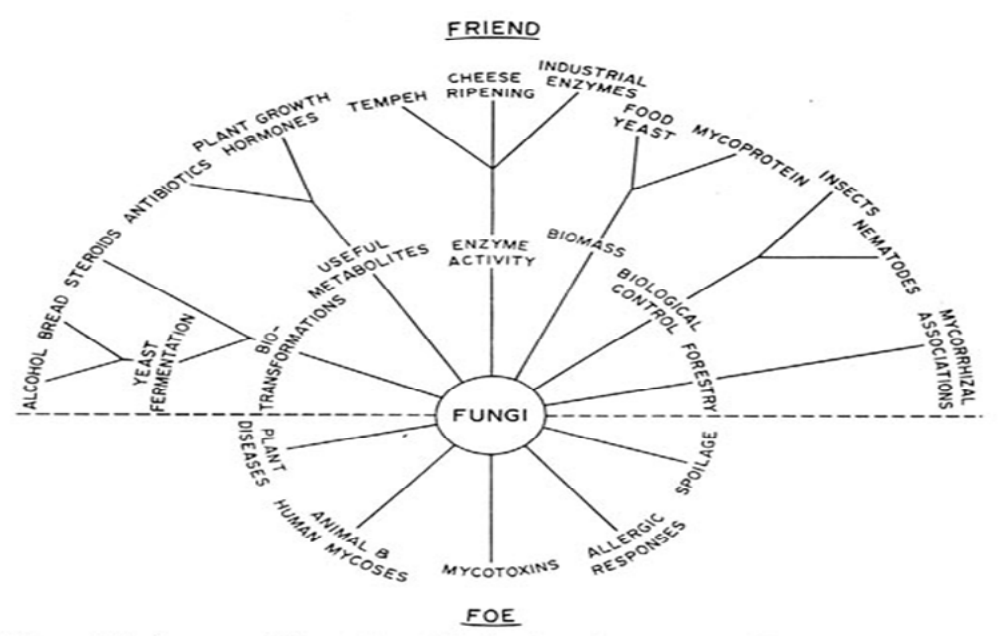

Fig. 1: Ray diagram showing the summary of the activities of fungi, relate to humans

Source: Retrieve 22.02.2017 from www.mycorrhizea.com 
Mycorrhizeal plants have many advantages over non-mycorrhizal plants, including better nutrient uptake especially Phosphorus (P), faster rehabilitation of degraded sites, greater tolerance to diseases and soil toxins, and greater survivability under stress conditions. Mycorrhizal research carried out over the years has confirmed their and nurseries and to prove the benefits of mycorrhizea in enhancing plant growth, thereby effectively reducing the costs incurred in the use of expensive phosphate fertilizers (Figure 1).

\section{Significance of ROC technique}

Wide use of these fungi with or without or in combinations with other manure and synthetic fertilizers is coming up to drastically reduce use and subsequent deleterious effects of industrial fertilizers in the agro ecosystem (Cranenbrouck, Voets, Bivort, Renard, Strullu \& Declerck., 2005; Ju, Kou, Christie, Dou \& Zhang., 2007; Kong, Zhu, Fu, Han Zhang \& He., 2008). In this regards, there have been several efforts by workers to have in-vitro cultures of AMF on specified culture media grown roots and then infected by AMF with colorizations in the rhizospheres (Gaur \& Adholeya, 1994). After drying such roots, these could be utilized as biofertilizers. However, culturing conditions could involve substantial economical inputs.

\section{Preliminary works}

Genetic transformation of roots with the soil bacterium Agrobacterium rhizogenes Conn. was achieved decades ago (Riker, Banfield, Wright, Keitt \& Sagen., 1930; Ark \& Thompson, 1961). In-vitro cultures of AMF are due to their rigid symbiotic obligate association which is further complicated because biotrophic and hypogenous nature of the micobionts involved. To overcome these debilitations several attempts have been made during the last few years to obtain symbiosis under in-vitro conditions. The use of root organ culture has proved successful. Lists of such Glomalean species are cultivated on root organ cultures (Fortin Becard, Deterck, Dalpe, St-Arnaud \& Chughlan., 2002). Various plants such as Allium cepa L. (Liliaceae), Cucumis sativus L. (Cucurbitaceae), Daucus carota L. (Apiaceae), Linum usitatissimium L. (Linaceae), Lycopersicon esculantum Mill. (Solanaceae), Medicago truncatula Gaertn. (Leguminoceae), Solanum tuberosum L. (Solanaceae), Tagetes pastula L. (Asteraceae), Trifolium pretense L. ( Leguminoceae), T. repens L. (Leguminoceae) etc. have been used to establish monoxenic (i.e. root organ) cultures of AMF.

\section{Status of in vitro propagation of AMF in the world}

In vitro propagation of $\mathrm{AMF}$ is categorized into two groups. 


\section{Establishment in trifolium pretense root}

Mosse and Hepper (1975) first successfully performed root organ culture using a system based on dual culture of Glomus mosseae Nicolson and Gerd. spores with excised roots of $T$. pretense. Due to their obligate symbiotic nature, less than 5 percent of AMF were successfully cultivated using the duel culture approach. Most data generated under monoxenic culture conditions have been obtained with Glomus and Gigaspora species. While in situ observations on in vitro-produced cultures of Scutellospora species, have been reported.

\section{Establishment in Daucus carota root}

The monoxenic method involved growing sterile AMF spores on dual culture plates with transformed $D$. carota root. Depending on the strain of $A$. rhizogenes used for the transformation, different principals of opines (novel compound synthesized during transformation of bacterium into the host plant) can be found in the tissues of the hairy root such as agropine, mannopine, cucumopine or mikimopine (Dessaux, Petit \& Tempe., 1992).

Root organ culture has obvious advantages over traditional system, permitting production of contaminant-free propagules. So far $25 \mathrm{AMF}$ species have been successfully cultivated in monoxenic culture (Fortin, Becard, Declerck, Dalpe, St-Arnaud \& Chughlan., 2002).

\section{PROCEDURES AND MATERIALS}

\section{Apparatus required}

Petri plates, potted plants, Beaker, $250 \mathrm{ml}$ screw cap bottles, 250 $\mathrm{ml}$ conical flask, Knife, test-tubes are required to carry out the in vitro propagation of arbuscular mycorrhizal fungi using ROC Technique.

A. rhizogenus bacteria, spores of Glomus, Mycorrhizal root of $T$. pretense, Filter paper, Distilled water, Dissecting and compound microscope, Incubator, Laminar air flow; Autoclave, hot air oven etc. are the required for the in vitro culture.

\section{Chemicals}

Ethanol/Sodium hypochloride, Tween 20 and antibiotics (streptomycin/ gentamycin) are required.

\section{Requirements in vitro establishment of mycorrhiza}

Following steps should be carried out for starting from pot cultures maintained under greenhouse (Figure 2): 


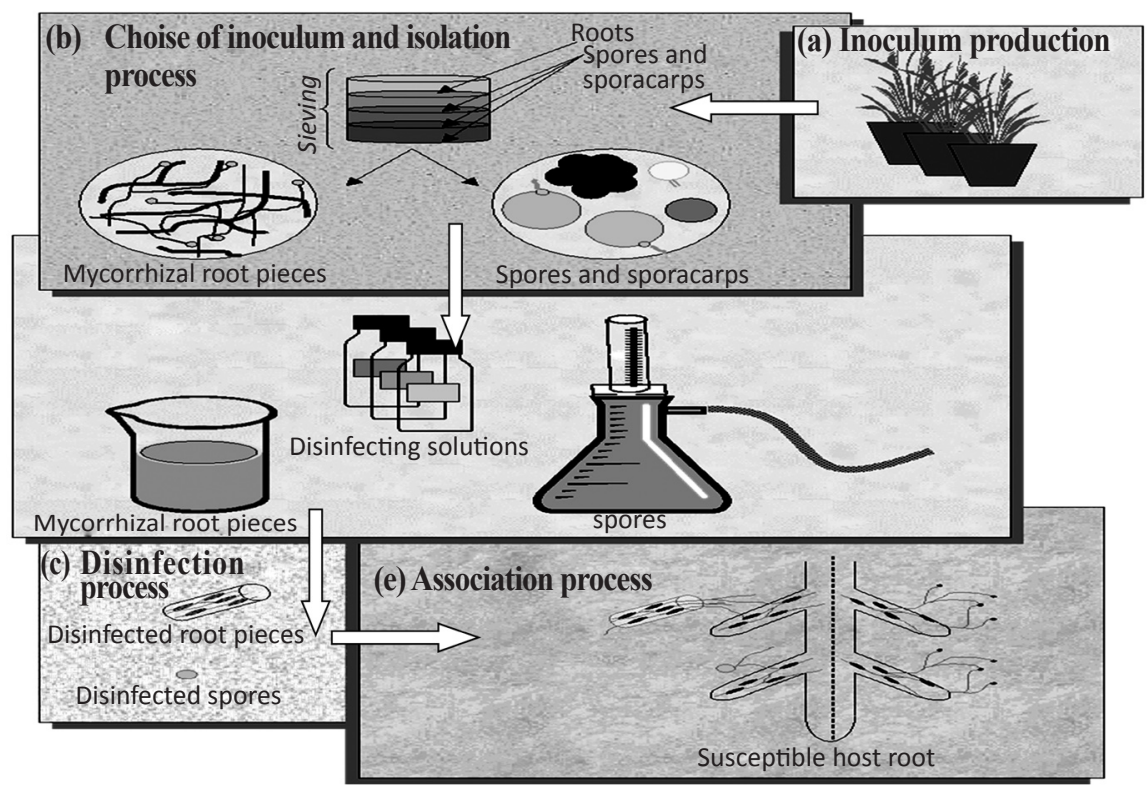

Fig. 2: Protocol of Inoculums production, selection, isolation, disinfection of propagules, incubation and association to a susceptible host on the synthetic growth medium of AM fungi

Source: Retrived: 22.02.2017 from www.Mycorrhizea.com.

\section{Step first-inoculums production}

Spores and mycorrhizal roots are subjects to the initiation for monoxenic cultures come from trap plants, grown under controlled greenhouse condition on a natural soil or in the presence of isolated AMF propagules (Figure 2a).

\section{Step second - Selection of starter inoculums and its isolation}

- Spores and mycorrhizeal roots are collected from the trap plants by wet sieving (Figure 2b).

- These are examined under dissecting microscope and recovered several isolations in water.

- Old spores and debris are eliminated, for this Gigaspora and Scutellospora species (which do not contain vesicles), are preferred.

- Practically Glomus, Acaulospora and Entrophospora species (which contain vesicles), are preferred for mycorrhizeal roots having young, white and turgescent with no discernable surface contaminants and wounds are selected. 


\section{A PROTOCOL ON IN VITRO PROPAGATION OF ARBUSCULAR ...}

\section{Step third - Subsequent disinfection of the Propagules}

- The disinfection process is the most critical step to achieve a successfully in vitro culture.

- Several disinfecting agents, (particularly) are used (for surface sterilization process): ethanol, calcium hypochlorite, chloramine $\mathrm{T}$, added with few drops (approx. 1ml) of Tween 20 and antibiotics (streptomycin and gentamycin).

- $\quad$ Each step is separated by several rinsing in sterile water $\left(121^{\circ} \mathrm{C}\right.$, for 15 min) (Figure 2c).

\section{Step forth - Incubation of propagules}

- After disinfection, the propagules i.e. spore and mycorrhizal root pieces are incubated on a synthetic growth medium until hyphal re-growth is observed (Figure 2d)

- This step is conducted in order to select and eliminate the contaminated propagules.

\section{Step fifth - Association to a susceptible host root on the synthetic growth medium}

- Germinating spores/mycorrhizal root pieces showing hyphal regrowth are reassociated with a susceptible host on the synthetic growth medium i.e. modified Strullu-Romand (MSR) media.

- In general the propagule is transferred into the Petriplate near an actively growing root or by transferring the actively growing host root in the vicinity of the propagules (Figure 2e).

- Sporulation is observed after several weeks or months depending on the strain consider.

\section{Mechanisms}

AMF are successfully propagates (cultivates) using the duel culture approach by using Glomus mosseae spores with excised roots of T. pretense.

- The monoxenic method involved growing sterile AMF spores on dual culture plates with transformed $D$. carota root.

- A. rhizogenes, (a gram -ve soil bacterium) which includes hairy root disease of dicotyledonous plants, is used to induce hairy roots.

- In roots transformer with this bacterium a segment of the bacterial DNA, the T (transformed DNA) of the root including plasmid (Ri), are incorporates into the host plant cells (Chilton, Tepfer, Petit, David, Casse-Delbert \& Tempe, 1982). Integration and expression of this DNA 
in the plant genome lead to the development of hairy root phenotype and synthesis of novel low molecular weight compounds called opines (Tepfer \& Tempe, 1981).

- These adventitious roots are then culture in vitro on medium devoid of plant hormones, where they rapidly grow with a characteristic, highly branched and non-geotropic pattern.

- The combination of transformed carrot roots and sterile AMF spores can be used to produce "dual in vitro cultures" that provide an efficient method of producing abundant spores $[(>5000)$ and mycelia on a $9 \mathrm{~cm}$ Petriplate] (Becard \& Fortin, 1988) (Figure $3 \& 4$ ).

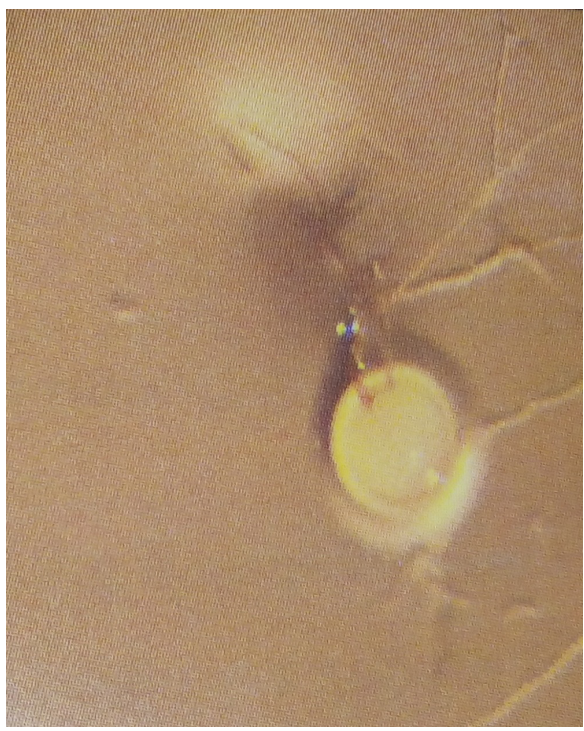

Fig. 3: In vitro spore germination

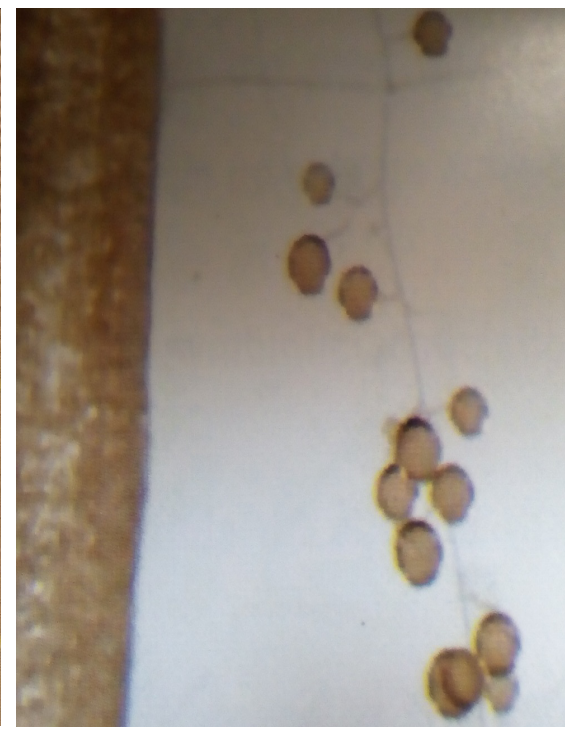

Fig. 4: In vitro sporulation

Source: Rodrigues, 2009.

\section{CONCLUSION}

The success achieved by using root organ culture technique in cultivation of AMF in vitro is not only restricted to the study of the symbiotic interactions, but also permits the increase of knowledge in the morphology, taxonomy, phylogeny and biochemistry fields together with some aspects of their ecology. This protocol is an effort to compile widely used in AMF research. This protocol will serve as a useful guide for mycorrhizeal researcher, teachers, and the student community.

\section{WORKS CITED}

Ark, P.A., \& Thompson, J.P.(1961). Detection of hairy rootpathogen, Agrobacterium rhizogenes, by the use of fleshy roots. Phytopathology. (51), pp. 69-71. 


\section{A PROTOCOL ON IN VITRO PROPAGATION OF ARBUSCULAR ...}

Becord, G., \& Fortinin, J.A. (1988). Early events of vesicular arbuscular mycorrlinze formation in $\mathrm{Ri}$ T-DNA trarsformed roots. New Phytopathlogy. 108, pp. 211-218.

Chilton, M.D., Tepfer, D.A., Petit, A., David, C., Casse-Delbert, F., \& Tempe, J. (1982). Agrobacterium rhizogenes, ensert T-DNA into the genome of host plant root cells. Nature. 295, pp. 432-434.

Cranenbrouck, S., Voets, L., Bivort, C., Renard, L., Strullu, D.G., \& Declerck, S. (2005). Methodologies for in vitro cultivation of arbuscular mycorrhizal fungi with root organs. Soil Biology Vol. 4 In Vitro Culture of Mycorrhizas. In S. Declerck, D.G. Strullu, A. Fortin (Ed,) Springer-Veriag, (pp. 341-375). Berlin, Heidelberg.

Dessaux, Y., Petit, A., \& Tempe, J. (1992). Opines in Agrobacterium biology. in: molecular signals in plants microbe communications. In D.P.S. Verma (Ed.) CRC Press Boca Raton, pp. 109-136.

Fortin, J.A., Becard, G., Declerck, S., Dalpe, Y., St-Arnaud, M., Chughlan, A.P., \& Piche, Y. (2002). Arbuscular mycorrhiza in root-organ cultures. Can. J. Bot. ( 80), pp. 1-20.

Gaur, A. \& Adholeya, A. (1994). Estimation of VAM spores in the soil-A modified method. Mycorrhiza News, 6 (1), pp. 10-11.

Ju, X.T., Kou, C.L., Christie, P., Dou, Z.X., \& Zhang, F. S. (2007). Changes in the soil environment from excessive application of fertilizers and manures to two contrasting intensive cropping systems on the North China Plain. Environ Pollut. 145(2), pp. 497-506.

Kirk, P.M., Cannon, P.F., David, J.C., \& Stalpers, J.A. (2001). Ainsworth and Bisby's dictionary of the fungi, ( $9^{\text {th }} \mathrm{ed}$.). Wallingford, UK: CABI Publishing.

Kong, W.D., Zhu, Y.G, Fu, B.J., Han, X.Z., Zhang, L., \& He, J.Z. (2008). Effect of long-term application of chemical fertilizers on microbial biomass and functional diversity of a black soil. Pedosphere. 18(6), pp. 801-808.

Mosse, B., \& Hepper, C.M. (1975). Vesicular-arbuscular mycorrhizal infections in root organ cultures. Physiol. Pl. Pathol. (5), pp. 215-223.

Plenchette, C., Declerck, S., Diop, T.A., \& Strullu, D.G. (1996). Infectivity of monoxenic subcultures of the arbuscular mycorrhizal fungus Glomus versiforme associated with Ri-T-DNA-transformed carrot root. Appl. Microbiol. Biotech. (46), pp. 545-548.

Riker, A.J.., Banfield, W.M., Wright, W.H., Keitt, G.W., \& Sagen, H.E. (1930). Studies on infectious hairy root of nursery apple trees. J. Agric. Res. (41), pp. 507-580.

Tepfer, D.A., \& Tempe, J. (1981). Production d'agropins per des raciness ormeeb Sous L' actien d' Agrobacterium rhizogenes, Souche Au. C.R.A cad. Sci, Paris. 292, pp. 153-156. (orginal not seen). 